\title{
Family-School Connections: Different Theoretical Perspectives and their Implications for Teacher Education
}

\author{
Osama M. Almahdi ${ }^{1}$ \\ ${ }^{1}$ Educational Studies Department, Bahrain Teachers College, University of Bahrain, Kingdom of Bahrain \\ Correspondence: Osama Almahdi, Edcuational Studies Department, Bahrain Teachers College, University of \\ Bahrain, P.O Box 32038, Kingdom of Bahrain. Tel: 00973-1743-7286. E-mail: oalmahdi@uob.edu.bh
}

Received: September 17, 2019; Accepted: October 5, 2019; Published: October 18, 2019

\begin{abstract}
Family-school connections had received increasing attention in the past decades due to their potential benefits for students' learning. However, the educational and research community is still working to give a clear explanation for what family-school connections really stand for, which is understood to be a complicated concept. This paper begins by presenting different definitions of family-school connections. Afterwards it discusses various theoretical perspectives in this educational area, which include: Piaget cognitive development theory, Vygotsky's sociocultural theory, the funds of knowledge theory, Bourdieu's social capital theory, Bronfenbrenner's ecological theory, the overlapping family and school spheres, Hoover-Dempsey \& Sandler framework, and the structural and relational theoretical approach in understanding family-school connections. The paper concludes with a discussion about the implications of these theoretical perspectives on research and on teacher education.
\end{abstract}

Keywords: family-school connections, parental involvement, educational theory, Arabian Gulf countries

\section{Background: Defining Family-School Connections}

There is an extensive body of research that demonstrates the important role that family and school connections can play in students' overall functioning in different academics, behavioral, and social adjustments areas (e.g. Desforges and Abouchaar, 2003; Ginsburg-Block et al., 2010). Many governments around the world (e.g. USA, UK, Canada, New Zealand, and Australia) are introducing policies to encourage partnership between schools, families and communities (Epstein et al., 2011, 2018). Research suggests that children whose families engage actively in their education tend to have better attendance, higher school graduation rates, fewer grade retentions, increased level of satisfaction with school, reduced number of negative behavior reports and higher scores on reading and Mathematics tests, and better psychological well-being (Hinderson \& Mapp, 2002). Bakker and Denssen (2007) indicated that like many other concepts in the social sciences, parental involvement is a valueloaded term. Kim and Sheridan (2015) argued that despite a seemingly wide agreement on the importance of family-school connections, there is less agreement on how these connections are conceptualized and defined. First, there are many differences in terminology (e.g. different researchers use different terms such as home-school relations, home-school connections, family-school partnerships, parental engagement, participation or involvement). Second, it seems that some researchers or educators may give more attention on a single perspective of such connections and overlook the complexity of whole picture of family-school connections (e.g. focusing only on one aspect such as school communication to parents).

Taking into account these various conceptualizations, Kim and Sheridan (2015) suggested that family-school connections must have two main features: (1) parents and teachers are mutually engaged in the educational process, and (2) efforts are aimed at supporting students' learning and positive development. Parents can engage in various ways in their children's education; these include behavioral engagement (e.g. attending school conferences, working with their children on homework or talk about school), cognitive engagement (e.g. parents' attitudes, beliefs, aspirations for their children education), and relation engagement (e.g. establishing positive relationships with school staff). Teachers can also engage with parents in similar ways: behavioral engagement (e.g. inviting parents to come to school, talking with them in conferences or sending written notes), cognitive engagement (e.g. when teachers showcase positive attitudes toward parents' involvement), and relation engagement (e.g. establishing strong relationships with parents). These mutual connections serve to promote students' academic, social and emotional development. 
Edwards and Kutaka (2015) discussed the terminology used to describe family-school relationship focusing on three terms: involvement, engagement, partnership. They indicated that 'involvement' is a broad term that categorizes various types of activities parents use to connect with schools in ways requested by school staff (e.g. school centered and teacher initiated). These activities were organized by Joyce Epstein et al. $(2011,2018)$ in a framework identifying six distinct types of parental involvement: (1) Parenting: when families establish home environments to support children's learning, the provision of school supplies, general support and supervision at home. (2) Communicating: effective forms of school-family communication about school programs and children's progress in their studies. (3) Volunteering: recruit and organize parent help and support to the school. (4) HomeBased Learning: when the school provide information and ideas to families of how to help children at home with homework and provide them with other helpful learning activities. (5) Decision Making: including parents in school decision making processes and encouraging parents to take leadership roles, governance, and advocacy. (6) Collaborating with the community: when the school identifies and integrates resources and services from the community to strengthen school programs and students' learning.

Yamauchi et al. (2017) noted that Epstein's model can be useful in promoting a culture of shared responsibilities among families, teachers, and other members of the students' communities, a classification which can also be used as a framework for developing policies, improving leadership practices, and initiating new research agenda in the area of family-school connections. Epstein's model can be fairly easy to understand and implement; however, Yamauchi et al. (2017) suggested that this model positions the school as the one who is in control of parents. This one-way control would contradict the idea of limiting the focus of family-school connections to the benefits of the children and their school related activities, rather than focusing on a real partnership that are valuable for all involved stakeholder: parents, community members, and teachers. This model also seems to overlook investigation of the different meanings that might be held by those stakeholders of each type of involvement proposed by Epstein and the power distribution, relationships and changing roles of various players.

Edwards and Kutaka (2015) indicated that engagement and partnership are the newer terms in the literature of school-family relationships. They defined family engagement as "involve[ing] genuine collaboration between families and schools/agencies whereby parents and teachers share responsibility for the healthy development and educational aspirations of children" (p. 38). The term engagement, according to this view indicates a less schoolcentric perspective on the school-family relationship and refers to the broad range of activities including all forms of family contribution, involvement, and partnerships.

In the partnership model proposed by Hornby (2011), parents are considered as the experts in regards to their children and teachers are the experts in their fields of education. Partnership in this model is based on a set of principles such as trust, respect, competence, communication, commitment, equality and advocacy. Teachers need to work in a professional way and attain knowledge, values and skills that enable them to create a strong relationship with the parents. In addition, Christenson and Sheridan (2001) defined school-family partnership as developing as "intentional and on-going relationship between school and family designed to directly or indirectly enhance children's learning and development, and/or address the obstacles that impede it" (p.38). Goos et al. (2004) summarized specific types of family-centered connections with school and community described in the literature: (a) Creating supportive learning environments at home, which includes the supervision and structure that parents give children to support their education (e.g. by providing structured time for homework and learning, and limiting TV viewing). (b) Parental support for the child, including emotional and academic support and the expression of parental aspirations and expectations regarding the child's current school performance. (c) Parents as role models for the value of education, where parents can serve as role models for why schools are important and share their own experiences that reinforce the value of education. (d) Home practices that support learning development and parent-directed activities and discussions that connect children to out-of-school learning opportunities. For example, parents can enrich their children's learning by linking what they are learning in schools with what they do at home.

Grolnick and Raftery-Helmer (2015) found that family-school partnerships are characterized by a number of features that ranges from a student's focus, to the very belief that families and students are jointly important and must share responsibility for achieving student success, also an emphasis on active collaboration, and a preventative solution-focused approach where families and schools work together to create optimal learning conditions. Bauch and Goldring (1998) suggested a classification of four types of school governance based on parents' and teachers' empowerment: (1) Bureaucratic: is the traditional mode of governance where neither parents nor teachers hold power. Teachers will have nothing more than classroom autonomy here. (2) Teachers' Professionalism: here parents have low participation while teachers have high empowerment. Teachers' power is based on their expertise and they might tend not to attempt to involve the parents as this may decrease their 
professional status. (3) Parent Empowerment: where parents are more active in schools and teachers have low empowerment. Parents tend to challenge school practice and teachers feel disempowered. (4) Partnership: here is where parents and teachers are both highly empowered. Dual empowerment is seen as a feature of teachers' professionalism that is based on collaboration with all stakeholders including parents and students (Addi-Raccah \& Ainhoren, 2009).

Family learning is a concept used in educational literature in the UK; it is defined as being "about families enjoying learning together. Those who seek to promote family learning acknowledge the central role of the family in a child's learning, validate the nature of that learning by engaging families in dialogue about learning, and facilitate the participation of families in the design and enjoyment of learning" (Mackenzie, 2009, p. 9).

\section{Theoretical Perspectives on Family-School Connections}

This section presents and discusses the following theoretical perspectives on family-school connections: Piaget cognitive development theory (Piaget, 1981), Vygotsky's socio-cultural theory (Vygotsky, 1978), the 'funds of knowledge' theory (Moll et al., 1992), Bourdieu's social capital theory (Bourdieu, 1986), Bronfenbrenner's ecological theory (Velez-Agisto, et al., 2017), the overlapping family and school spheres (Epstein, 2011), HooverDempsey \& Sandler framework (Hoover-Dempsey \& Sandler, 1995; 1997; 2005), and the structural and relational approach in understanding family-school connections (Kim \& Sheridan, 2015). The implications of these theoretical perspectives for teacher education will be presented then.

Let us start with Piaget cognitive development theory which is widely used in the educational research. The basic idea of Piaget theory was that young children are active learners with a constant drive to match their internal constructions (their own view of the real world) and external realities they face in their surroundings (Piaget, 1981). Cognitive conceptions of learning stress that learning is an active, constructive, and goal-oriented process that is dependent upon the mental activities of the learner, Piaget emphasized the children's independent exploration of their environment. Human cognition according to this theory develops through two processes: (a) assimilation, which includes the process of assimilating external actions into thoughts and fitting new mental models into the existing mental structures, and (b) accommodation, which includes the process of structuring the adopted mental ideas in the mind. This theory also offered broad stages for children's cognitive development (sensory-motor, preoperational, concrete operational, and formal operations) to understand changes in children's thinking from early childhood through adolescence (McDevitt \& Ormord, 2013). Battle-Bailey (2004) suggested that parents play an important role in promoting their children's learning through shared interactions. Homework, for instance, can allow for parent/child interactions as this will facilitate children's construction of knowledge. Parents can also help their children in areas such as problem-solving, interactive tasks related to the learners' environment, focusing on learners' interests and encouraging them to independently monitor their learning while interacting with their parents.

The cognitive development theory emphasizes parents' and teachers' contributions during the critical stages of child development especially in early years of a child's life as an important stage for future success. Personality and attitude towards learning are well established in the first five years of the child's life therefore parents have to teach their young children needed skills, while arranging educational activities and experiences (Epstein, 2011).

Another well-known theory in the educational field is Vygotsky's socio-cultural theory. The socio-cultural theory explains the learning process as an action that happens when the individual actively participate in in a wider circle of social practices. This active participation is mediated by two important processes: social interactions with other such as parents, peers or teachers; and cultural tools such as language, signs, symbols and learning aids. Learning, according to this theory, is not merely a set of intellectual and mental processes detached from its social, cultural and economic contexts (Eun, 2010). Children according to this view learn through interacting with others, they communicate using language, signs and symbols and actively engage in various cultural and social meaningful activities. They also use different tools to organize and control their behaviors, all in which are tools created and developed in specific social, cultural and economic contexts. Certain types of higher thinking abilities such as deliberative attention, verbal and conceptual thinking cannot develop without the constructive assistant of such social and cultural mediation (Ivic, 2000). Accordingly, by emphasizing the interrelations and strong dependence in learning and development, this theory supports the idea that children's home environment is important in promoting learning and parents contribute greatly to the development of their children's learning abilities (Tekin, 2011).

Knowledge according to the socio-cultural theory is shared and created among experts (e.g. teacher, parent, peer) as they all engage in inquiry-based activities that serve to solve authentic and meaningful problems. Knowledge is also seen as a human creation process rather than a given fact and its located in the cultural and social contexts 
of learning not just in the mind of the learner (Eun, 2010). Vygotsky (1978) defined the concept of the zone of proximal development (ZPD) as "the distance between the actual development level as determined by independent problem-solving and the level of potential development as determined through problem-solving under adult guidance or in collaboration with more capable peers" (p. 86). In other words, as the child develops cognitively, he or she takes more responsibility for learning or doing increasingly difficult tasks.

The 'funds of knowledge' theory is based on Vygotsky's socio-cultural theory. It attempts to apply the sociocultural theoretical concepts to change and improve children's meaningful learning. In line with Vygotsky's ideas (e.g. zone of proximal development and the role of mediation in learning) Moll and his colleagues (Gonzalez, Moll \& Amanti, 2005) regarded every household as an educational setting with important educational potential. The term 'funds of knowledge' was used to describe forms of knowledge and skills which can be found in local households and "these historically accumulated and culturally developed bodies of knowledge and skills essential for households or individual functioning and wellbeing" (Moll et al., 1992: 133). All this knowledge and skills attained are connected with authentic activities such as farming, construction, trade and business. Their approach also focuses on how families develop social networks which can facilitate the development and exchange of resources including knowledge, skills and labor. In the UK, the Home School Knowledge Exchange project (Feiler et al., 2008) explored ways for enhancing primary literacy through exchanging ideas and skills between families and schools. The basic principles of the school program were: (a) All families possess important 'funds of knowledge' which can be drawn on to enhance children's learning at home. (b) Communication needs to take place in two directions, from home to school and from school to home. (c) Diversity amongst children and families is an opportunity and not a problem. (e) Exploring the richness of children's home lives can be a highly motivating process for learning in school.

Yamauchi et al. (2017) noted that the 'fund of knowledge' theory can be helpful in shifting the representation of parents and families from a 'deficit view' - e.g. parents lacking education or awareness of the importance of schooling - to one of having resources and are able to utilize everyday social and cultural experiences to enrich children's learning. The theory gives recognition to family and community resources and the importance of including them into formal school learning. The theory also offers fairly accessible ideas for teachers to use when working with the students and their families, especially those of cultural and social backgrounds different from the teacher's backgrounds. Yamauchi et al. also noted some points that needs attention when using this theory. For example, the concept of 'funds of knowledge' can be misunderstood from a deficit viewpoint to say that some social, cultural, linguistic and economic groups of families would have more funds than others. The 'funds of knowledge' approach may also position teachers as the persons responsible to empower families. This may put the family-school relationship in an unequal position with the family as more dependent on the school instead of having an equal or balanced relationship.

The Social Capital theory, developed by Bourdieu, is widely used in the field of sociology. Power is a central element in Bourdieu's concept of the social field. School can be interpreted as an arena for power fights between different actors, such as between parents and teachers. In the educational system, an increase of engagement between school and families will better enhance the overall relationship between the two parties and bring with it a potential for a levelling out of power balance between schools and families. In Bourdieu's words, this is the crises that may affect the structure of the field and; therefore, teachers' monopoly, which may lead teachers to adopt a defensive discourse (Baeck, 2010). According to Bourdieu, academic success or failure in school is not just influenced by children's cognitive abilities, but is also affected by the methods of production and investment in different types of cultural and social capital, for instance, attitudes, preferences, behaviors and social networks (Bourdieu, 1986). For Bourdieu, schooling legitimizes the inter-generational reproduction of inequalities, with the source of these inequalities lying in differentiated home backgrounds; as a result, teachers are accorded a more passive role.

Bronfenbrenner's ecological theory looked at a child's development within the context of the system of relationship that forms his or her environment. This environment consists of a number of complex layers and each of them has its own significant effect on the child. It has similar views with the socio-cultural theory that culture is not separate matter from an individual and culture itself is a product of human activity. Bronfenbrenner defined ecological theory as the study of human development in context or enduring environments. For the child, this surrounding environment consists of different layers: the first layer is the microsystem which includes immediate settings such as home, school and playground. The second layer is the mesosystem, where two or more microsystems are connected. As to the third layer, the exosystem, which is similar to the mesosystem except that at least one setting is not directly related to the individual. The fourth layer is the macro-system, and it is the outmost layer that encompasses the customs, culture and beliefs of the community or larger society. Therefore, the very essence 
of Bronfenbrenner's theory is the importance of daily interactions and experiences over time (Velez-Agisto, et al., 2017). Yamauchi et al. (2017) argued that this theory emphasized the importance of understanding the accumulated experiences of the different stakeholders, and this idea plays a key role in understanding family-school relationships. Understanding the influence of social contexts can help teachers and families in achieving meaningful and sustainable relationships and overcoming barriers to successful partnerships.

Epstein (2011) discussed three perspectives that guided researchers and practitioners in their thinking about family and school relations: (1) Separate responsibilities of families and schools, which assumes that schools and families have separate responsibilities. Teachers maintain their professional educational roles in the classrooms and parents maintain their personal attention to their children at home. (2) Shared responsibilities of families and schools: this view emphasizes the coordination and cooperation between schools and families, encouraging communication and collaboration between the two institutions. Teachers and parents are believed to share common goals for their children and they need to work together to achieve this goal effectively. (3) Sequential responsibilities of families and schools: this perspective emphasizes the critical stages of both parents' and teachers' contributions to child development. The parents' role in children's socialization in the early years is critical to prepare children for school. At the time of the children's formal entry into school, the teacher assumes the main responsibility of educating them.

Based on the previous idea, Epstein (2011) developed a model of overlapping family and school spheres that accounts for families, schools and students in terms of their history, development and changing experiences. The external sphere of the model consists of overlapping or non-overlapping spheres which represent the family, school and community. The overlap among these spheres represents the level of partnership between all three institutions. These overlaps are influenced by many factors such as time, age and grade level and historical influences, experiences, philosophies, and practices of families, schools and communities. Yamauchi et al. (2017) noted that this model takes into account the importance of these three contexts in a child's development process and how they all share responsibilities in the process of children's socialization. Epstein acknowledged that some practices of school, family and community are needed to be done separately, but suggested for central practices to be done in a collaborative manner by individuals across the spheres. Epstein also acknowledged that schools should be open to higher levels of partnerships from different stakeholders and that teachers should be open to share educational responsibilities for students' learning with families and other community members. Yamauchi et al. (2017) indicated that this model can be considered as an expansion of Bronfenbrenner's ecological theory with specific focus on family-school connections and it seems still to focus on school-centered activities and perspectives, thereby limiting the perspectives and voice of families.

Hoover-Dempsey \& Sandler $(1995,1997,2005)$ and, Walker et al. (2005) proposed a theoretical model of the parental involvement process. This model generally indicates a relationship between parents' perceptions and practices in relation to children's education. They identified seven psychological factors that might influence parents' decisions to become involved in their children's education. Parents get involved in their children's education through 'home-based' and 'school-based' activities. Parents' choice of involvement is influenced by their 'motivational and personal beliefs', their 'perceptions of invitations for involvement from others', and their 'perceived life context'. Parents' motivational/personal beliefs include 'parental role constructions' and 'parental self-efficacy'. 'Parental role constructions' refers to parental roles which parents believe they should play in relation to their child's education. 'Parental self-efficacy' refers to the outcomes parents believe they can bring to their children through involvement in their children's education. Another element in this framework is 'parents' perceptions of invitation for involvement from others' which refers to parents' perception whether their involvement is welcomed in the school or not. 'Invitation from others' includes parents' perceptions of general school invitations, perceptions of specific child invitations, and teachers' invitations. The last element is 'parents perceived life context' which includes parents' self-perceived knowledge and skills, as well as parents' selfperceived time and energy (Fan, 2012).

Yamauchi et al. (2017) thought that the previously mentioned model of parental involvement is helpful in understanding the psychological ideas related to why parents engaged in both home-centered and school- centered educational practices. The framework is comprehensive in its description of how families' beliefs and experiences affect their involvement in their children's learning or schooling and how these practices can influence children's learning outcomes or behavior. It also shows the complexities of family-school connections and the different ways that families can be engaged because they come from different educational, social, cultural and economic backgrounds. Yamauchi et al. (2017) discussed one of the drawbacks of this model as its so comprehensive and includes many factors that most of the research focuses on specific aspects of the model and can face difficulties in investigating the whole model at the same time, so that the complete model has yet to be fully tested. 
Kim and Sheridan (2015) proposed a structural and relational approach to understand family-school connections. They suggested that researchers have investigated family-school connections across two areas: those focusing on the activities in which parents and teachers engage (structural approaches), and those focusing on the relationships which parents and teachers engage (relational approaches). Structural approaches are often termed parental or family involvement, they are largely structural like when parents support children's homework or when they volunteer in schools. These efforts can be school-based or home-based and are often guided by schools and are conducted systematically. One of the problems of the structural approaches is that there is more emphasis on structured or scripted activities rather than interpersonal processes that support learning within the parent-child interactions. Whereas relational approaches emphasize the interpersonal relationships between parents and teachers who are responsible for different aspects of a child's development. These approaches focus on partnerships, enhancing opportunities and success of children across social, emotional, behavioral and academic domains. Bringing together structural and relational approaches would offer parents and teachers better opportunities to achieve their educational goals.

\section{Implications}

Family-school connections received increasing attention by educators, researchers, policy-makers in many educational systems around the world. There is a general agreement in regards to the importance of these connections, however, the meaning of the theoretical concepts that underlie these connections are still not clearly defined or explained. Various researchers explored this educational field and they reached interesting findings which can have positive impacts on educational practices. These conceptual bases can also help students in teacher preparation programs to reflect on their personal experiences and understand the complexities of their relationships with families. The previous literature can guide teacher education program to emphasize the importance of moving from school-centered parental involvement model to a partnership model, which promotes responsibility sharing between families and schools. These programs should also highlight the importance of children's environments as sources for authentic learning environments and how parents and other family members can play key roles in their children's learning in and out-of-school. These authentic home resources can support children's learning if both family and school recognized their importance and work intentionally in connecting school formal learning with home informal learning. Student teachers should be aware of how parents can play key roles in the social and personal development of their children and in preparing them with the social skills, attitudes towards learning, and the positive expectations and aspirations. Student teachers should learn about the different theoretical perspectives that have been used by researchers to understand family-school connections. Each of these perspectives has strengths and limitations. Piaget cognitive development theory (Piaget, 1981) and related literature focused on the cognitive development of the child and how family members can build the foundation for children's personality and cognition especially in the first five years of childhood. When family members interact with their children and engage in problem-solving and active-learning with their children this will help them create their own authentic learning structures and experiences. Therefore, student teachers should learn more about children's homes and families and try to link school learning with out of school practices. In addition, Vygotsky's socio-cultural theory (Vygotsky, 1978) gave much attention to the social and cultural mediation processes that takes place in the children's environment with more expert members such as parents and teachers. Children can achieve better learning outcomes when they work with others and interact with different cultural tools and social settings. Student teachers' knowledge of this theory is important as it would help them to understand the scaffolding learning methods that may take place at their students' homes.

Moll et al. (1992) extended some ideas from the socio-cultural theory and proposed the funds of knowledge perspective, where teachers and parents work together to build upon the cultural and social resources available in the children's homes and environments, and utilize them to offer an authentic learning experience that goes beyond the formal and traditional curriculum. Teacher education programs need to give student teachers the opportunity to explore the 'fund of knowledge' of the students who come from different cultural and socio-cultural backgrounds and build on it in their classrooms.

Bourdieu's social capital theory (Bourdieu, 1986) highlighted the power issues that can hinder the relationship between families and schools especially when parents come from disadvantaged cultural, social or economic backgrounds. The ideas of social capital and social networks can be used by the student teachers to learn more about these disadvantaged communities and invest in their strengths instead of looking at them from a deficit view. Bronfenbrenner's ecological theory also gave valuable insights as it disassembled the components of the different environments that surround the child, and further explained the interactions between them and how they affect each other. The overlapping family and school spheres perspective proposed by Epstein (2011) tackled familyschool relations from different levels and provided an overall picture of the complexities of such relationships. 
Hoover-Dempsey \& Sandler $(1995 ; 1997 ; 2005)$ framework focused on the psychological aspects of family-school connections while Kim \& Sheridan (2015) offered a new perspective which explored the structural and relational approaches in understanding family-school connections. Therefore, it is important for student teachers to understand the influence of social contexts which can help teachers and family members - or hinder them - in implementing meaningful family engagement and overcoming barriers to successful partnerships.

Final remarks related to researcher's educational context: Engaging families in multiple aspects of the educational experience surfaces as critical work for schools especially nowadays as they are facing increasing levels of accountability. The researcher is currently working in the educational system in the Kingdom of Bahrain - Bahrain Teachers College - which is giving more attention to promoting strong relationships between schools and families. Creating strong relationship with the local community is one of the strategic goals of the Ministry of Education. In addition, Bahrain Quality Assurance Authority considers these relationships as an indicator of school success in creating positive learning environment, this is emphasized in the students' support and guidance aspect of the school review framework developed by that authority. The researcher believes that in order to meet the national and international standards of education the educational system needs promote strong relationships between school, families and communities. Schools in the region need to understand the social context of the diverse learners who come from different cultural, social and economic backgrounds and who may go through different in- and out-ofschool learning experiences. Educators and researchers also need to understand how school, parents and the community interact with each other and how these interactions can lead to better students' outcomes. Most of the theoretical perspectives discussed in this paper are predominantly western accounts. There is a lack of research, contextualized theoretical frameworks, and a need for further exploration into the topic of family-school connections in the Gulf Cooperation Council (GCC) countries: Saudi Arabia, Bahrain, Kuwait, United Arab Emirates, Oman and Qatar. Although all the GCC countries are reforming their educational systems, there have only been a few numbers of current research studies that are accessible for the international research community in the area of family-school relationships. For example, Al-Mahrooqi, Denman, \& Al-Maamari (2016) who studied Omani parents' involvement in their children's English education. In addition, Al-Harrasi \& Al-Mahrooqi (2014) investigated Omani parents' involvement in their children's schooling. Similarly, Al-Qaryouti \& Kilani (2013) studied the role of Omani parents in fostering emergent literacy skills. In the United Arab Emirates, Al-Sumaiti (2012) wrote a theoretical paper which reviewed international research and, examined the impact of increased parental involvement on the education and development of children, with a particular focus on Dubai schools. In another study in the United Arab Emirates, Al-Taneiji (2013) studied the role of leadership in engaging parents in the United Arab Emirate schools. In Kuwait, Al-Daihani (2005) explored supervisors' attitudes toward family involvement in middle schools around Kuwait. Also, in Kuwait, Al-Fadley et al. (2018) investigated the views of the teachers working in Kuwait's public schools regarding the effectiveness of parental involvement in their children's learning of English as a foreign language (EFL) in primary school. In Bahrain, Al-Mahdi (2010) explored ways of linking home and school mathematics in a Bahraini Primary School. Future research on schoolfamily connections should be directed toward developing theoretical frameworks that are relevant to the social, cultural and educational contexts in the GCC countries.

\section{References}

Addi-Raccah, A., \& Ainhoren, R. (2009). School governance and teachers' attitudes to parents' involvement in schools. Teaching and Teacher Education, 25, 805-813. https://doi.org/10.1016/j.tate.2009.01.006

Al-Daihani, S. (2005). Supervisors' attitudes toward family involvement in Kuwait middle schools. (Unpublished doctoral dissertation). Virginia Polytechnic and State University, Blacksburg, Virginia.

Al-Fadley, A., Al-Holy, A., \& Al-Adwani, A. (2018). Teacher perception of parents' involvement in their children's literacy and their reading instructions in Kuwait EFL primary school classrooms. International Journal of Education and Practice, 6, (3), 120-133. https://doi.org/10.18488/journal.61.2018.63.120.133

Al-Harrasi, S., \& Al-Mahrooqi, R. (2014). Investigating Omani parents' involvement in their children's schooling. European Journal of Scientific Research, 117 (2), 272-286.

Al-Mahdi, O. (2010). Linking home and school mathematics: A qualitative case study in a Bahraini Primary School. Germany: Lambert Academic Publishing.

Al-Mahrooqi, R., Denman, C., \& Al-Maamari, F. (2016). Omani parents' involvement in their children's English education. SAGE Open, 6(1), 1-12. https://doi.org/10.1177/2158244016629190

Al-Qaryouti, I., \& Kilani, H. (2015). Role of Omani parents: fostering emergent literacy skills. Education 3-13: International Journal of Primary, Elementary and Early Years Education, 43(3), 336-348. 
https://doi.org/10.1080/03004279.2013.815248

Al-Sumaiti, R. (2012). Parental involvement in the education of their children in Dubai. Dubai School of Government Policy Brief, 30. Retrieved July 30, 2018 from http://www.khda.gov.ae/CMS/.../Parental_Involvement_in_the_Education.pdf

Al-Taneiji, S. (2013). The role of leadership in engaging parents in United Arab Emirate schools. International Education Studies, 6(1), 153-165. https://doi.org/10.5539/ies.v6n1p153

Baeck, U. (2010). 'We are professionals': A study of teachers' views on parental involvement in schools. British Journal of Sociology of Education, 31(3), 323-335. https://doi.org/10.1080/01425691003700565

Bakker, J., \& Denessen, E. (2007). The concept of parent involvement: Some theoretical and empirical considerations. International Journal about Parents in Education, 1(0), 188-199.

Battle-Bailey, L. (2004). Review of research: Interactive homework for increasing parent involvement and students reading achievement. Childhood Education, 81(1), 36-40. https://doi.org/10.1080/00094056.2004.10521292

Bauch, P., \& Goldring, E. (1998). Parent-teacher participation in the context of school governance. Peabody Journal of Education, 73(1), 15-35. https://doi.org/10.1080/01619569809538875

Bourdieu, P. (1986). The forms of capital. In J. Richardson (Ed.). How people learn: Brain, mind, experiences and school. Washington, D.C.: National Academy Press.

Christenson, S., \& Sheridan, S. (2001). Schools and families: Creating essential connections for learning. New York: Guilford.

Desforges, C., \& Abouchaar, A. (2003). The impact of parental involvement, parental support and family education on pupil achievement and adjustment: A literature review. London: Department of Education and Skills.

Edwards, C., \& and Kutaka, T. (2015). Diverse perspectives of parents, diverse concepts of parent involvement and participations: Contrasts between Italy and the United States. In S. M. Sheridan, \& E. M. Kim (Eds). Foundational Aspects of Family-School Partnership Research (pp. 1-14). New York: Springer.

Epstein, J. (2011). School, family and community partnerships. United States: Westview Press.

Epstein, J., Galindo, C., \& Sheldon, b. (2011). Levels of leadership: Effects of district and school leaders on the quality of school programs of family and community involvement. Educational Administration Quarterly, 47(3), 462-495. https://doi.org/10.1177/0013161x10396929

Epstein, J., Sanders, M., Sheldon, S., Simon, B., Salinas, K., Janson, N., Van Voorhis, F., ... Williams, K. (2018). School, family, and community partnerships: Your handbook for action. United Kingdom: Crowin.

Eun, B. (2010). From learning to development: A sociocultural approach to instruction. Cambridge Journal of Education, (40), 401-418. https://doi.org/10.1080/0305764x.2010.526593

Fan, Q. (2012). Parents perceptions and practices in homework: Implications for school-teacher-parent partnership. (Unpublished doctoral dissertation). The Graduate College of the University of Illinois at Chicago. Illinois, Chicago.

Feiler, A., Andrews, L., Greenhough, P., Hughes, M., Johnson, D., Scanlan, M., \& Yee. W. (2008). The home school knowledge exchange project: Linking home and school to improve children's literacy. Support for Learning, 23, 12-18. https://doi.org/10.1111/j.1467-9604.2008.00363.x

Ginsburg-Block, M., Manz, P., \& McWayne, C. (2010). Parenting to foster achievement in reading and mathematics. In S. L. Christenson \& A. Reschly (Eds). Handbook of school- family partnerships (pp. 1752013). New York: Springer.

Gonzalez, N., Moll, L., \& Amanti, C. (2005). Funds of knowledge: Theorizing practices in households, communities and classrooms. NJ: Routledge. https://doi.org/10.4324/9781410613462

Goos, M., Lincoln, D., Coco, A., Frid, S., Galbraith, P., \& Horne, M. (2004). Home, school and community partnership to support children's numeracy. Australia: Department of Education, Science and Training.

Grolnick, W., \& Raftery-Helmer, J. (2015). Core components of family-school connections: Toward a model of need satisfying partnership. In S. M. Sheridan, \& E. Moorman Kim (Eds). Foundational Aspects of FamilySchool Partnership Research (pp. 15-34). New York: Springer. https://doi.org/10.1007/978-3-319-13838-1_2

Henderson, A., \& Mapp, K. (2002). A new wave of evidence: The impact of school, family, and community connections on students achievement. Austin: TX: Southwest Educational Development Laboratory. 
Hoover-Dempsey, K., \& Sandler, H. (1995). Parental involvement in children's education: Why does it make a difference?. Teachers College Record, 97(2), 310-331.

Hoover-Dempsey, K., \& Sandler, H. (1997). Why do parents become involved in their children's education? Review of Educational Research, 67(1), 3-42. https://doi.org/10.3102/00346543067001003

Hoover-Dempsey, K., \& Sandler, H. (2005). Final performance report for OERI: The social contexts of parental involvement: A path to enhanced achievement. Presented to Project Monitor, Institute of Education Sciences, U.S. Department of Education, March 22, 2005.

Hornby, G. (2011). Parental involvement in childhood education: Building effective school-family partnership. Berlin: Springer. https://doi.org/10.1007/978-1-4419-8379-4

Ivic, I. (2000). Lev S. Vygotsky. UNESCO: International Bureau of Education.

Kim, E., \& Sheridan, S. (2015). Foundational aspects of family-school connections: Definitions, conceptual frameworks, and research needs. In S. M. Sheridan, \& E. Moorman Kim (Eds). Foundational Aspects of Family-School Partnership Research (pp. 1-14). New York: Springer. https://doi.org/10.1007/978-3-31913838-1_1

Mackenzie, J. (2009). Family learning: Engaging with parents. Scotland: Dunedin.

McDevitt, T., \& Ormrod, J. (2013). Child development and education. Pearson International Edition (5 $5^{\text {th }}$ ed.). New Jersey: Pearson.

Moll, L., Amanti, C., Neff, D., \& Gonzalez. (1992). Funds of knowledge for teaching: Using qualitative approach to connect home and classroom. Theory Into Practice, XXXI(2), 132-141. https://doi.org/10.1080/00405849209543534

Piaget, J. (1981). Their relations during child development. Palo Alto, CA: Annual Reviews.

Tekin, A. (2011). Parent involvement revisited: Background, theories, and models. International Journal of Applied Educational Studies, 10, 1-13.

Velez-Agisto, N., Soto-Crespo, J., Vizcarrondo-Oppenheimer, M., Vega-Molina, S., \& Coll, C. (2017). Bronfenbrenner's bioecological theory revision: Moving from macro into micro. Perspectives on Psychological Science, 12(5), 900-910. https://doi.org/10.1177/1745691617704397

Vygotsky, L. (1978). Mind in society: The development of higher psychological processes. Cambridge, Mass: Harvard University Press.

Walker, J., Wilkins, A., Dallaire, J., Sandler, H., \& Hoover-Dempsey, K. (2005). Parental involvement: Model revision through scale development. Elementary School Journal, 106(2), 402-436. https://doi.org/10.1086/499193

Yamauchi, L., Ponte, E., Ratliffe, T., \& Traynor, K. (2017). Theoretical and conceptual frameworks used in research on family-school partnership. School Community Journal, 27(2), 9-34.

\section{Copyrights}

Copyright for this article is retained by the author(s), with first publication rights granted to the journal.

This is an open-access article distributed under the terms and conditions of the Creative Commons Attribution license (http://creativecommons.org/licenses/by/4.0/). 